\title{
Cardboard Dinosaur: The Use of Simple Three-Dimensionality and Macroscopy Tools as a Low-Cost Strategy for Presentation of Classical Biological Themes
}

\author{
Roberta Pires Correa ${ }^{1 *}$, Patrícia Pinto Teixeira ${ }^{2 *}$, Anderson da Costa Lacerda ${ }^{3}$, \\ Julia Barral Dodd Rumjanek ${ }^{4}$, Vivian Mary Barral Dodd Rumjanek ${ }^{5}$, Fernanda Serpa Cardoso², \\ Lucianne Fragel Madeira ${ }^{3,4}$, Helena Carla Castro ${ }^{1,2,3,4 \#}$

\footnotetext{
${ }^{1}$ Post-Graduation Program in Biosciences and Health Teaching PGEBS, Fiocruz, Rio de Janeiro, RJ, Brazil

${ }^{2}$ Professional Master Degree in Diversity and Inclusion Biology Institute, Federal Fluminense University, Niterói, RJ, Brazil ${ }^{3}$ Post-Graduation Program in Science and Biotechnology, Biology Institute, Federal Fluminense University, Niterói, RJ, Brazil Brazil

${ }^{5}$ Post-Graduation Program in Biological Chemistry, Biochemistry Institute, Federal University of Rio de Janeiro, Rio de Janeiro, RJ, Brazil

Email: robertacorrea.inclusao@gmail.com, labiomol2003@yahoo.com.br, costadelacerda@gmail.com, lfragel@id.uff.br,

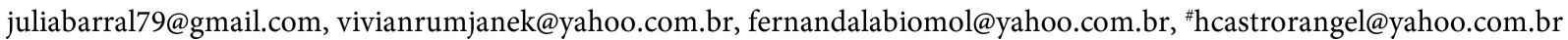 \\ ${ }^{4}$ Post-Graduation Program in Science, Technologies and Inclusion, Biology Institute, Federal Fluminense University, Niterói, RJ,
}

How to cite this paper: Correa, R. P. Teixeira, P. P., Lacerda, A. C., Rumjanek, J. B. D., Rumjanek, V. M. B. D., Cardoso, F. S., Madeira, L. F., \& Castro, H. C. (2020). Cardboard Dinosaur: The Use of Simple Three-Dimensionality and Macroscopy Tools as a Low-Cost Strategy for Presentation of Classical Biological Themes. Creative Education, 11, 250-261.

https://doi.org/10.4236/ce.2020.113019

Received: December 5, 2019

Accepted: March 10, 2020

Published: March 13, 2020

Copyright $\odot 2020$ by author(s) and Scientific Research Publishing Inc. This work is licensed under the Creative Commons Attribution International License (CC BY 4.0).

http://creativecommons.org/licenses/by/4.0/

\begin{abstract}
According to the literature, materials that explore visual effects are being more produced for teaching purposes, especially the computational ones. The application of these materials has significantly increased at different educational levels, from elementary to post-graduation. In this study, we aim to evaluate the level of student interest in the presentation of a classical theme of the biological sciences, Dinosaurs, by using Two-dimensional (2D), Three-dimensional (3D) or computational models. Therefore, we built three models of an Allosaurus skeleton including: 1) a 3D macroscopic "Dino" model (1 m per $1.5 \mathrm{~m}$ long) made with cardboard; 2) a 2D colorful Dino figure printed on an A4 size paper, and 3) a computational dancing dinosaur simulation, a "Virtual Dino" model, made with six sequential photographic repeated frames. A questionnaire and an in loco dynamic evaluation were created and applied to analyze the students' preference. Thirty-seven undergraduate students of Biological Sciences and Medicine courses had their reaction (choice) filmed and analyzed after looking at these three models. The results show that there is a high preference for the 3D-macroscopic "Dino", suggesting that visual exploration is still more attractive than a computational tool to stimulate interest in
\end{abstract}

*These two authors contributed equally. 
a topic. The preference for the three-dimensional macroscopic model still raises applicable perspectives and further challenges that may and should be explored in the area of science education, not only for deaf, blind and/or visually impaired people, but for each and every student.

\section{Keywords}

Three-Dimensional, STEM, Dinosaurs, Teaching, Learning

\section{Introduction}

There are different definitions about teaching materials including that they are pedagogical products used in education as well as instructional materials elaborated for didactic purposes (Richetti, 2018).

Currently, more and more teachers and professors contribute actively to the elaboration of support teaching materials. According to Kenski (2015), the traditional teaching process in most countries consists of oral expositions of the theoretical content, performing traditional practices with simple equipment. However, the current generation of students does not seem willing to continue to adopt a passive attitude in the classroom as they have grown up in an environment with active interaction with computers, video games and network resources. Thus, modern computational, audiovisual resources and hands-on experience have been largely included and have been used on a daily basis at schools, colleges and universities worldwide (Moreira et al., 2013, Sossai \& Barbosa, 2017).

Lately, teaching materials have improved in quality and quantity. They are increasingly used throughout elementary, secondary and postsecondary educations to assist on teaching and learning of students of different ages (Heinsfeld \& Pena, 2017). These materials organize and reinforce the knowledge presented in class also including alternative methodologies (Nóvoa, 2017).

According to some authors, such as Gottheim \& Pereira (2013) and Richetti (2018), the use of new and alternative methodologies should be a stimulus for teaching. They should promote integration between content and practical activities to allow the student to participate in the teaching-learning process, stimulating teamwork and creativity.

Importantly, some of the pedagogical approaches that involve these new didactic materials are expensive or not accessible to all students, due to their high cost. More recently, the educational area has explored three-dimensionality. Since we live in a three-dimensional world, but mainly virtual, the construction of these didactic materials allows better visualization and learning about the contents presented in the classroom and/or in non-formal teaching spaces (Rino et al., 2017). These models intend to reproduce reality in a specialized and concrete way, making it more comprehensible to the student (Feitosa et al., 2017).

The use of techniques of Virtual Reality (VR), both commercially and scien- 
tifically, has allowed three-dimensional visualization and interactivity, whereas providing the user greater immersion in these three-dimensional virtual environments (Falcão \& Machado, 2010; Baierle \& Luz 2017). Elaborating an attractive didactic material conceptualized in the macroscopic and three-dimensional scales favors the visual appeal derived from the technology.

Due to the high cost of computational techniques, the construction and use of other simple and low-cost materials are still in need. Thus, the use of three-dimensional non-virtual models may also add more compensates for the limitations of the two-dimensional illustrations found in books and makes the teaching-learning process more attractive (Araújo et al., 2016, p. 88). Furthermore, a three-dimensional model may also be perceived by blind or visual impaired students.

Some authors consider that learning processes in science, particularly in biology, need to be understood by constructing linked representations at three levels of reality perception, including the macroscopic, the submicroscopic and symbolic levels (Sá et al., 2008; Gregório, Oliveira \& Matos 2016). Dinosaurs are a content of biology that always attract attention from children and young people, probably as a result of their presence in movies, books and cartoons. They allow explaining different concepts including geological eras, animal extinction as well as morphological characteristics. However, science education still uses few resources to present it to students. Thus, it is of interest to search for more attractive and low cost strategies for teaching these classical biology subjects.

Considering these perspectives, this study aimed to develop a dinosaur three-dimensional (3D) and macroscopic didactic model to analyze the preference of these characteristics compared to other forms of presentation of this topic in a science class, including two-dimensional (2D), and computational models.

\section{Materials and Methods}

\section{Construction of the Dinosaurs Models}

Three types of models Allosaurus were constructed, including a 2D, a 3D and a computational model. A small wood commercial model served as basis for making the "Virtual Dino" in the computer and the three-dimensional "Dino Tactile". For the "Dino Tactile", the proportions of the small wood model were increased and the largest augmented model was used as a template for cutting the cardboard (Figure 1).

The "Dino 2D" model was a picture in a two-dimensional format, printed on an A4 size sheet and exposed in the room (Figure 2(A)).

The "Virtual Dino" model was constructed by using several photos taken in different angles and positions of the miniature Allosaurus wood model creating a 3D perspective in the virtual environment. The "Virtual Dino" video (Figure 2(B)) was made with the aid of the student Murilo Gomes, by using the "Photoshop Cs5" and "Windows Movie Maker", programs included in the "Office 2007" package of "Windows 7". 


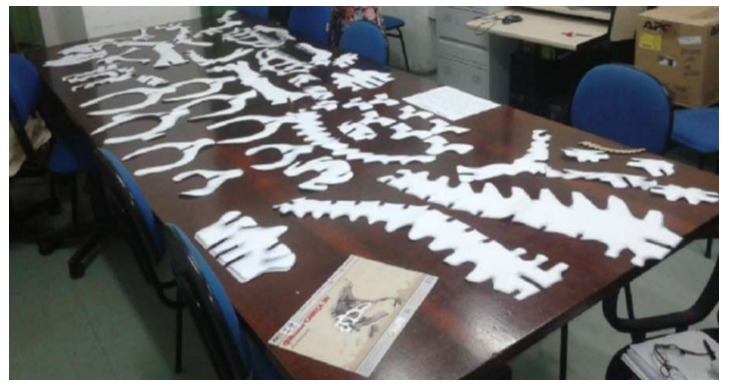

Figure 1. Cardboard molds for the construction of the "Dino Tactile".
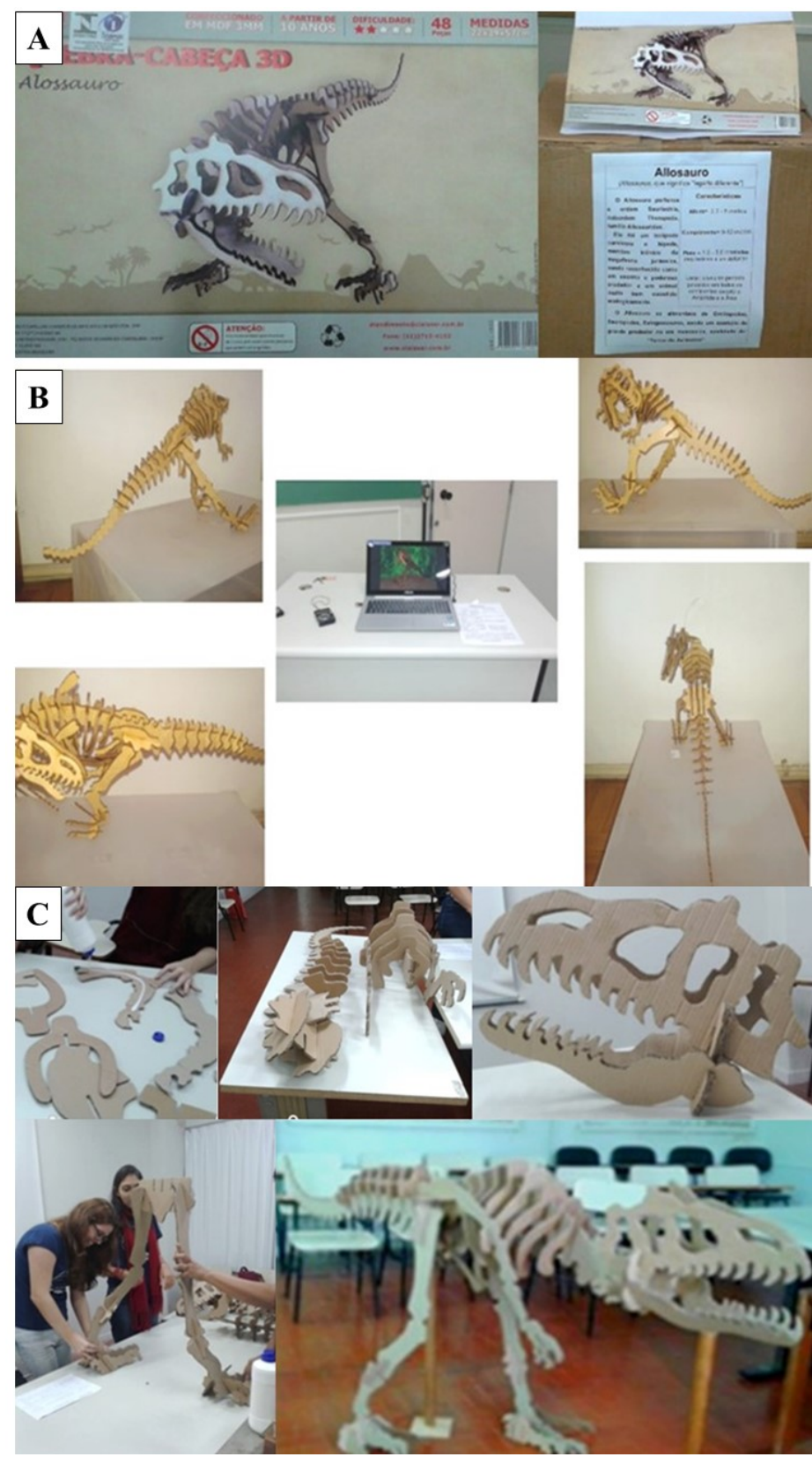

Figure 2. Three models of Dinosaur Allosaurus used in the evaluation. (A) Image of the Allosaurus and text used for presentation the 2D model format; (B) Images used to create the video of the "Virtual Dino"; (C) The process of assembling the 3D model "Dino Tactile". 
The "Dino Tactile" (Figure 2(C)) was made with recyclable cardboard and assembled with the aid of the volunteers undergraduate biology students Marina Manhães and Victoria Rosa.

The process of creating the "Dino Tactile" was divided into three steps, adding head, trunk and limbs (Figure 2(C)). The model was made by fitting these parts and layers of the cardboard were glued together in order to provide greater rigidity to the structure. To support the Dino weight, two rods were used on the day of the presentation.

The in loco test room was organized in a way which the students could visualize all three models at the same time by a small distance of approximately 3 meters (Figure 3 and Figure 4).

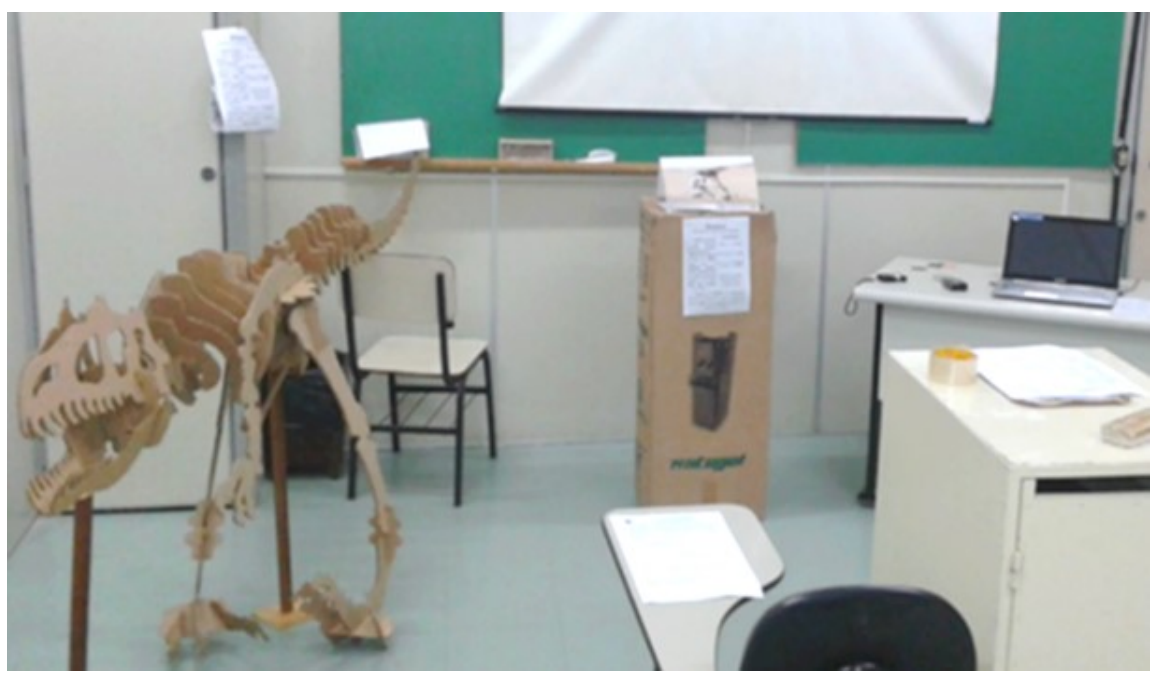

Figure 3. The three models disposition of the Dinosaur (3D, 2D and computational respectively) in the test room.

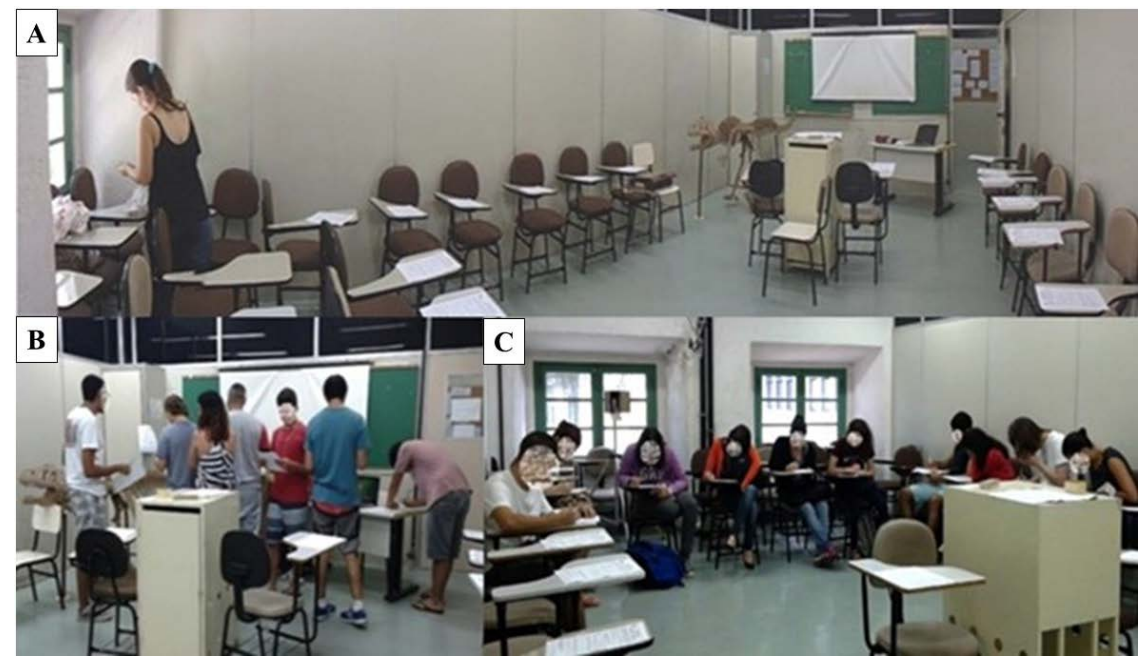

Figure 4. Test in loco of the three models of the Allosaurus. (A) Overview of room organization; (B) Testing the models of presentation ("Dino Tactile", "Dino 2D" and "Virtual Dino", respectively) of Allosaurus; (C) Evaluating the students' preference based on the applications of questionnaire. 
The evaluation of the models was performed with the application of a questionnaire and by video recording, which contributed to understanding which model first caught the attention of the students (Figure 4).

The questionnaire was elaborated into two sections: 1) information about the student; and 2) knowledge about the theme proposed.

Forty-two students initially volunteered to the study, however, 5 were excluded due being under 18 years old, totalizing 37 students. The research subjects were randomly selected, from both sexes, aged between 18 and 31 years old and of the under graduation courses of Biological Sciences $(n=26)$, Medicine ( $n$ $=10)$ and International Relationships $(\mathrm{n}=1)$. The exhibition test took place at a classroom of the Institute of Biology, UFF, Valonguinho Campus, Niteroi, Rio de Janeiro (Figures 4(A)-(C)).

The figure in 2D ("Dino 2D") was the first model in place, the second was the virtual version ("Virtual Dino") and the third was the three-dimensional and tactile version ("Dino Tactile") (Figure 4). A group of a maximum of 15 participants was invited to enter the room, observe the models by distance and see closely what arouses greater curiosity and/or interest. After visualizing all the models, the students answered the questionnaire (Figure 4(C)).

The research followed a predominantly qualitative approach that served as the basis for the construction of a quantitative instrument. Data were obtained from both writing and video recording of students' movement during the exposition of the models (Figure 4(B) and Figure 4(C)).

Two questions of the questionnaire, questions 4 and 10, allowed the student to add his/her opinion by justifying the answers. The analysis of the students' responses was mainly carried out as described by Lima (2018). The free software "Tagul - Word Cloud Art" (https://tagul.com) was used to analyze questions 4 and 10 of the questionnaire.

\section{Results and Discussion}

In this work, we developed a three-dimensional and macroscopic didactic model of an Allosaurus to analyze the preference of undergraduate students for these characteristics compared to other forms of presentation (2D and Virtual/computational).

Therefore, undergraduate students of Biological Sciences $(n=26)$, Medicine $(\mathrm{n}=10)$ and International Relationships $(\mathrm{n}=1)$ courses from a Brazilian public university $(\mathrm{n}=37)$ were tested for their preference as described on the materials and methods section (Figure 4). The students answered a questionnaire that was divided in two sections. In the first section, students answered about personal information, such as gender, age and undergraduate course. Most students were in the first semester of their courses, under 25 years old and female (68\%) (Figure 5).

The aim of the second section was to analyze the students' personal choice among the three model options and the best one for teaching activities. The 


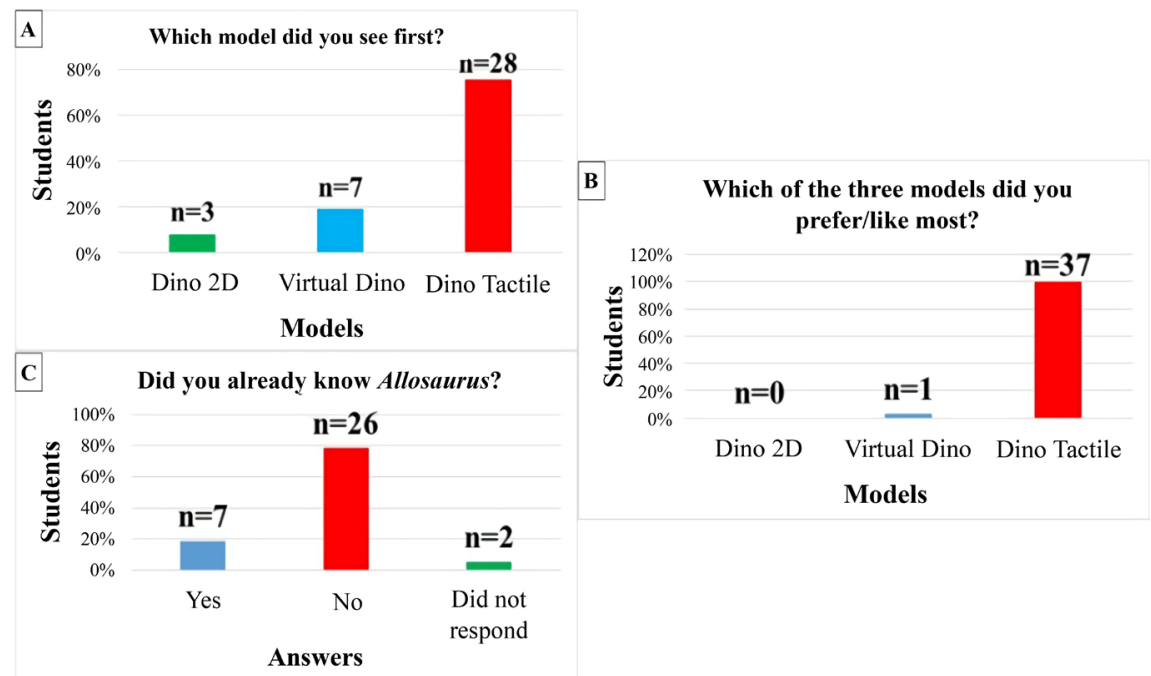

Figure 5. Undergraduate students answers about the Allosaurus and their preferences after the observation $(\mathrm{n}=37)$.

questionnaire showed that thirty-seven students (97\%) had preference for the "Dino Tactile" and only one student preferred the "Virtual Dino". We requested the students to place themselves into the position of a teacher or scientific disseminator and thus select the best form of presentation. Once more, "Dino Tactile" was preferred by the majority (29 students-76\%) compared to those that preferred the "Virtual Dino" (8 students-21\%), whereas only one student preferred the $2 \mathrm{D}$ flat version.

Interestingly, the "Dino Tactile" apparently managed to achieve the most important goal of this study, which was to overcome technology. Technological advancement sometimes leads to the misconception that humans are dependent on it, causing the old practices with recyclable and easy materials to be ignored or even forgotten.

Other perspectives have also important to be considered, including: 1) the use of a more well-crafted "Virtual Dino" model as well as 2) the use with unlimited period of time and easily revised according to the different needs, and 3) the fact that "Dino Tactile" is somewhat too rare today. Importantly, according to the students, previous knowledge about dinosaurs based in the cinema facilitated the recognition of the model (Figure 5).

The students were asked to analyze the models as a teacher, a scientific disseminator or as themselves and choose the best usability/application perspective. For this question, they could select more than one option or all options (Figure 6).

Most of the students selected "Dino Tactile" with lower preference for teacher perspective (43\%), but higher for the student point of view (78\%). The $2 \mathrm{D}$ presentation was always the least preferred which pointed the book as the last option for teaching in their opinion (Figure 6).

The next section allowed analyzing the students' opinion about the appropriate 


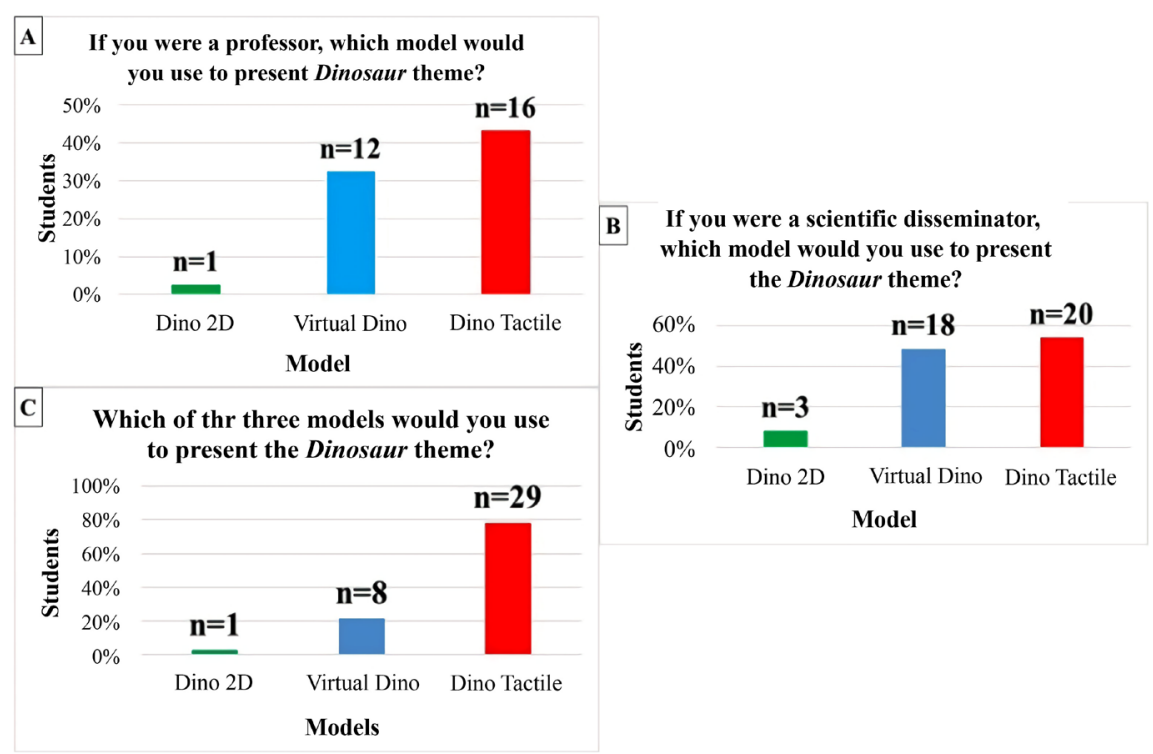

Figure 6. The usability of the Allosaurus models for teaching purpose from undergraduate students' opinion considering different perspectives. (A) professor/teacher; (B) Scientific disseminator; (C) Undergraduate student $(n=37)$.

age and the theme for using these models. According to them, these models are useful for teaching students of all ages (Figure 7).

Questions 4 (Which of the three models did you preferl like most? Why?) and 10 (Suggest some themes to be addressed with three-dimensional and macroscopic models) were analyzed by using a qualitative method (Figure 9 and Figure 10) as described by Palma et al. 2018. According to Silva \& Fossá (2015), the analysis of content is a delicate refining method and requires different information from the researcher; i.e. creativity to choose categories, dedication, patience, time, intuition and imagination to notice what is important.

Question 4 "Among the three models observed by you, which one did you prefer/like most? Justify." intended to confirm if there was a visual attraction for the 3D material (Figure 8). The analysis of the words used by the students in the questionnaires revealed the positive receptivity that occurred with the use of the "Dino Tactile" and features such as attraction, proportion, reality and interaction were the most pointed qualities by them for choosing 3D-Dino version. Thus, by analyzing the words used by the students in their answers we detected a positive relationship with "Dino Tactile" aspects.

The question 10 "Suggest some themes to be addressed with three-dimensional and macroscopic models)" requested suggestions of new themes for preparing and/or presenting similar materials. Importantly, different themes from biology area were pointed by these students including human, animal and cell topics, which indicated them as complex and in need for different teaching strategies and approaches (Figure 9).

Interestingly, 3D-dino model participated in an exposition of the Institute of Biology of Federal Fluminense University about undergraduate students production that was reported on the Facebook. Because of that, 3D-Dino was seen 


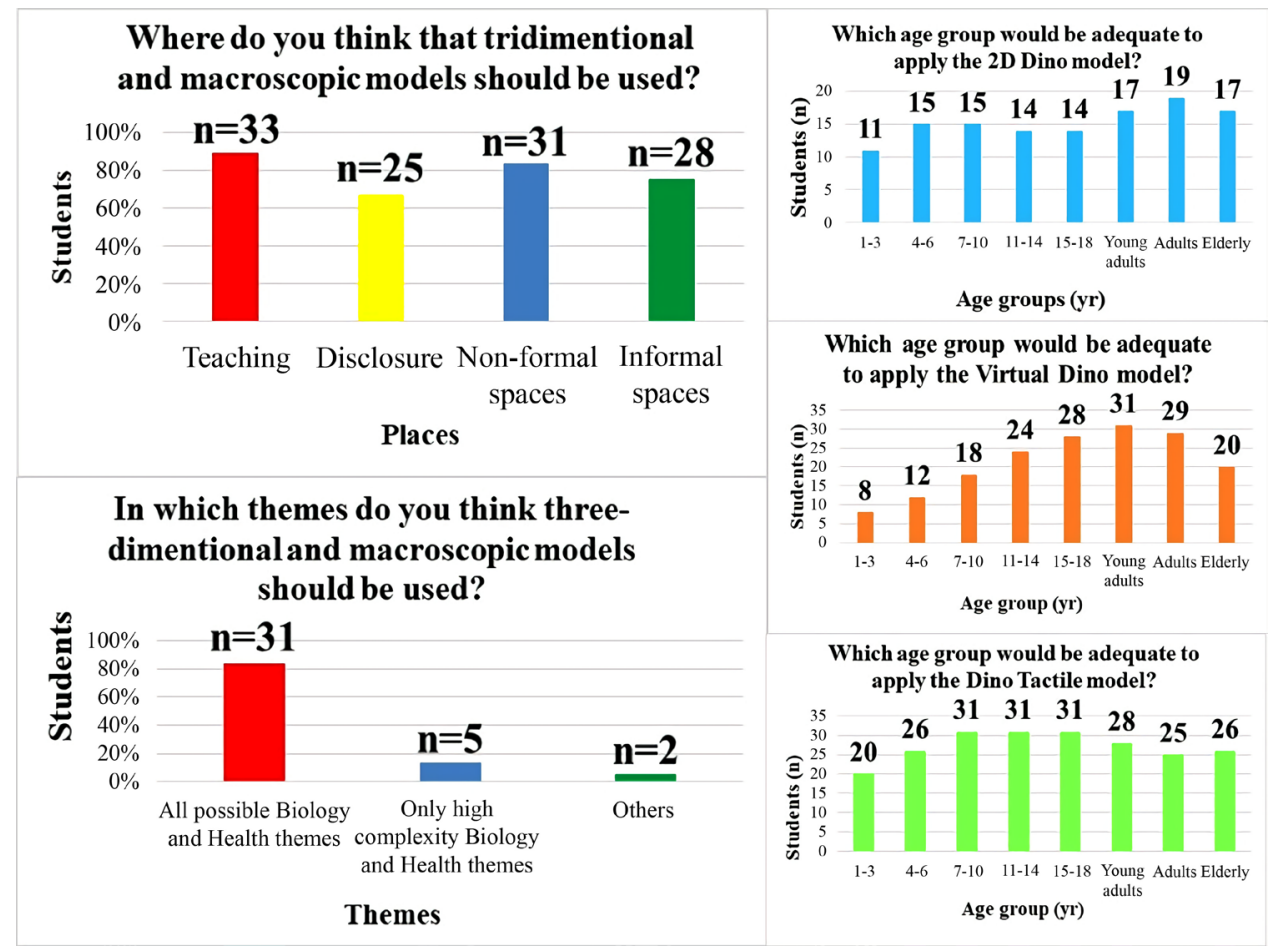

Figure 7. The utility for using the models for different themes and adequate age groups according to the volunteer students $(\mathrm{n}=37)$.

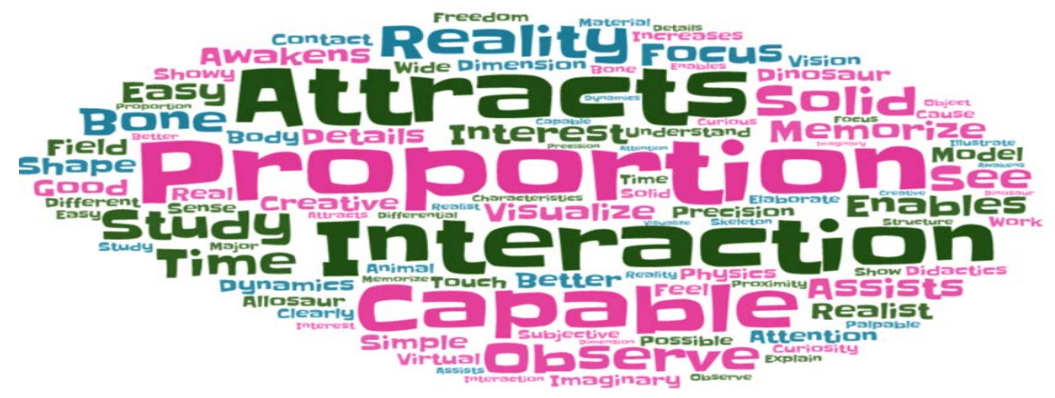

Figure 8. Word cloud analysis with the students justification answers for selecting 3D -Dino on Question 4 "Among the three models observed by you, which one did you prefer/like most? Justify.” using Tagul program.

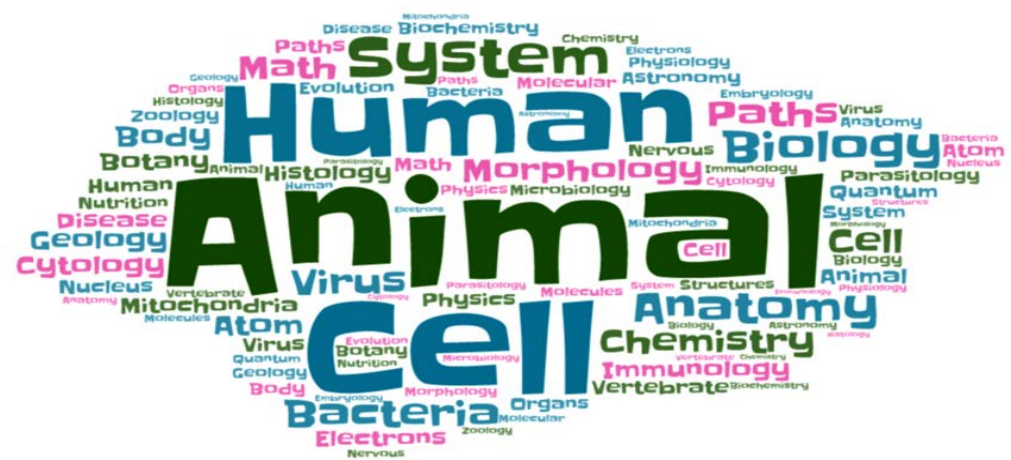

Figure 9. Word cloud analysis made with the students' responses for "Question 10: Suggest some themes to be addressed with three-dimensional and macroscopic model" using Tagul program. 
by an important museum of Niteroi city, The History and Arts Museum of the Rio de Janeiro state (Museu do Ingá) that requested it for an exposition about (new and old) forms to play. Therefore, 3D-Dino was donated to this Museum and it is currently on exhibition until March 2020 (Figure 10).

\section{Conclusion}

According to the literature, the production of teaching materials organizes and reinforces the knowledge presented in the classroom, highlighting the importance of the creation and use of alternative methodologies. This study explored macroscopy and three-dimensionality in a traditional didactic model to remind the utility of old known features for teaching new millennium student generations. An educational material does not need to involve modern technology for teaching and stimulate learning as long as it is able to generate better visualization of a concept applied. Based on our comparison study, the "Dino Tactile" attracted more attention than the $2 \mathrm{D}$ and computational versions. When participating, the students interacted and asked questions about the model, expanding their curiosity.

This study brought back an approach that was once common in classrooms but that has been abandoned. This type of material lost space to the colors, movement, dynamic and interactive space of a computer including the graphic design of games, which always attract the students' attention. There are numerous games sites designed for students. Although many digital materials are used in a didactic teaching-learning model, it was exciting to notice that the traditional can be adapted to classroom environment with dynamism and activities of the school routine. Our study suggests that the use of macroscopic and three-dimensional models may strengthen and consolidate teaching-learning topics, also reaching students who have lost interest or are less enthusiastic about difficult areas (e.g.

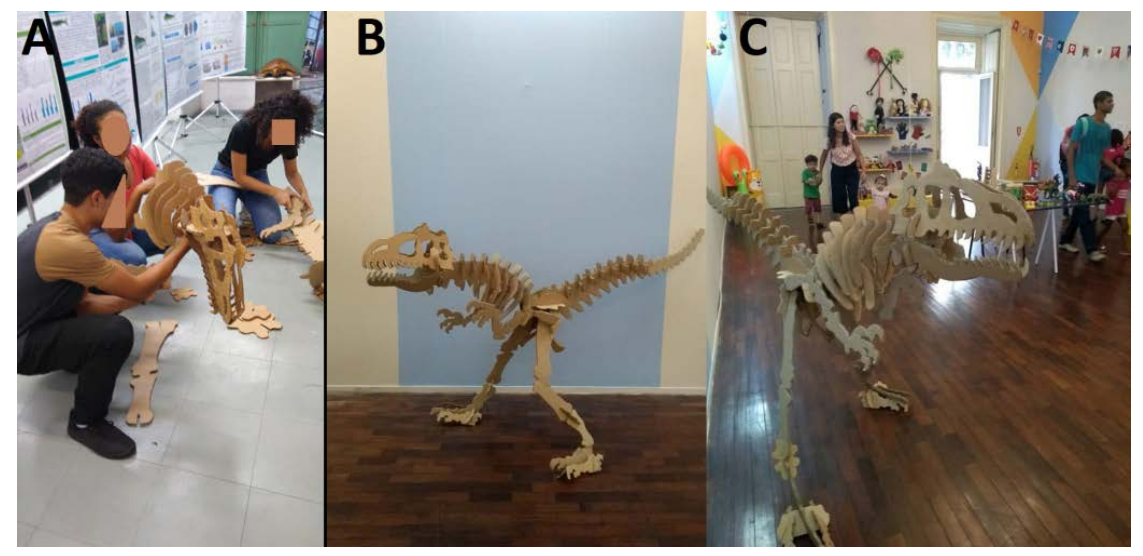

Figure 10. 3D-dino model participation in the exposition of the Institute of Biology of Federal Fluminense University about undergraduate students scientific and teaching production. It was used as a giant puzzle and played by Biology undergraduated students (A). As requested by the museum of Niteroy city, it was donated to The History and Arts Museum of the Rio de Janeiro state (Museu do Ingá) for exhibition until March 2020on a exposition about toys and childhood (B \& C). 
STEM). The presented model can motivate by changing the scenery in the classroom with the purpose of calling the attention and awakening the students' and teachers' interest again.

The use of traditional didactic materials can and should always be explored because it is necessary to elaborate easier and low-cost strategy methods. As far as inclusive education is concerned, the "Dino Tactile" can be used as a reference for the visually impaired with some tacticle improvement (e.g. sticking tacticle material such as sand on the surface) as it is an attractive and tactile material with a lot of macrodetails.

\section{Acknowledgements}

We thank to CAPES, FAPERJ and CNPq for the financial support and Julia Pettersson and Gustaf Sjöblom Gustafsson from Uppsala University for the English grammar revision.

\section{Conflicts of Interest}

The authors declare no conflicts of interest regarding the publication of this paper.

\section{References}

Araújo, B. R. G., Rabello, A. A., Nagem, R. L., Vieira, M. L. A., \& Gomes, F. C. O. (2016). Building Didactic Models: an Experience in Microbiology. Revista da Meta, 1, 84-90.

Baierle, I. L. F., \& Luz, J. C. (2017). Watt: 3D Immersion Shared and Accessible in Virtual Reality Emergence of Industrial Revolution (pp. 585-594). Brazil: Proceedings of the XXVIII Brazilian Symposium of Informatics in Education.

Falcão, E., \& Machado, L. S. (2010). Museum 3I: Publication and Visitation On line of Collections Tridimensional (pp. 1-6). Brazil: Proceedings of the VII Virtual and Augmented Reality Workshop.

Feitosa, E., Azevedo, M. M. R., Pereira, R. J. B., Góes, A. K., Hager, A. X., \& Martins, G. M. (2017). The Teaching Biology through Model Three-Dimensional: DNA Replication Process (pp. 21-23). Brazil: Proceedings of the International School of Education, Research and Extension.

Gottheim, L., \& Pereira, A. L. (2013). Analysis of a Unit for PLE Teaching: Exposing Limits and the Potentialities of Didactic Materials and Teacher Action. In L. Gottheim, \& A. L. Pereira (Eds.), Didactical Materials for Creation Processes and Contexts of Use in Foreign Language Teaching (pp. 63). Campinas: Mercado de Letras.

Gregório, E. A., Oliveira, L. G. P., \& Matos, S. A. D. (2016). Use of Simulators as Toolin Teaching of Abstract Concepts of Biology: An Investigative Proposition for The Teaching of Protein Synthesis. Experiences in Science Teaching, 11, 101-125.

Heinsfeld, B. D. S. S., \& Pena, A. L. (2017). Design Educational and Material Didactic Printed for Distance Education: A Brief Panorama. Brazilian Journal of Pedagogical Studies, 98, 783-804.

Kenski, V. M. (2015). The Urgency of Innovative Proposals for Teacher Training for All Levels of Teaching. Educational Dialogue Magazine, 15, 423-441.

Lima, M. L. (2018). Technology as a Didactic Resource for Geography Teaching on EJA. Undergraduate Dissertation, Campina Grande: State University of Paraíba. 
Moreira, V. R., Cinto, T., Leite, H. M. A., \& Arantes, D. S. (2013). Improving Engineering Education with New Approaches Using Computational Resources. Brazil: Proceedings of the VI CongressoTecnológico InfoBrasil TI \& Telecom.

Nóvoa, A. (2017). Firm Position as a Teacher, Affirming the Teaching Profession. Cadernos de Pesquisa, 47, 1106-1133. https://doi.org/10.1590/198053144843

Palma, M., Santana, A., Alves, G., Merçon, T., \& Castro, H. (2018) Nursing and Biochemistry: An Evaluation Strategy Using a Basic Discipline to Present to Freshman Students Their Future Professional Environment. Creative Education, 9, 497-512. https://doi.org/10.4236/ce.2018.93035

Richetti, V. C. (2018). Gender, Sexuality and Identity at School and In Portuguese Language: Construction and Analysis of a Didactic Material. Undergraduate Dissertation, Rio Grande do Sul: Federal University Rio Grande do Sul.

Rino, M. V., Valente, C. V. P. N., Fakhoury, R. S., Oliveira, D. A. D., Marar, J. F., \& Albino, J. P. (2017). Education and Digital Games: A Comparative between Representations Tridimensional and Its Effectiveness in Aid learning Process (pp. 26-31). Brazil: Proceedings of the $\mathrm{X}$ World Congress on Communication and Arts.

Sá, R. G. B., Lopes, F. M. B., Pereira, A. F., Jófili, Z. M. S., \& Carneiro-Leão, A. M. A. (2008). Abstract Concepts: Challenges for Teaching-Learning Biology.

Silva, A. M., \& Fossá, M. I. T. (2015). Content Analysis: Example of Technical Application for Qualitative Data Analysis. Qualitas Revista Eletrônica, 16, 1-14.

Sossai, O., \& Barbosa, J. B. (2017). The Teacher Practice Deviation Function. South American Journal of Basic Education, Technical and Technological, 94-101. 